\title{
Symptomatic chronically dissected giant pulmonary artery in a patient with pulmonary arterial hypertension
}

Alexander Steger, MD, ${ }^{\mathrm{a}}$ Marcus-André Deutsch, MD, ${ }^{\mathrm{b}, \mathrm{c}}$ Rüdiger Lange, MD, ${ }^{\mathrm{b}, \mathrm{c}}$ and Tareq Ibrahim, $\mathrm{MD}^{\mathrm{a}}$

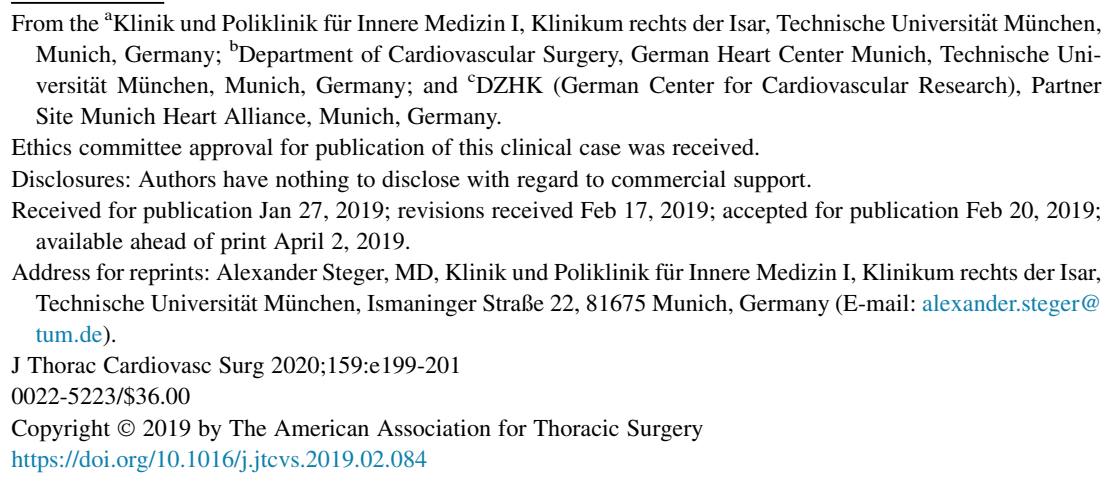

Video clip is available online.

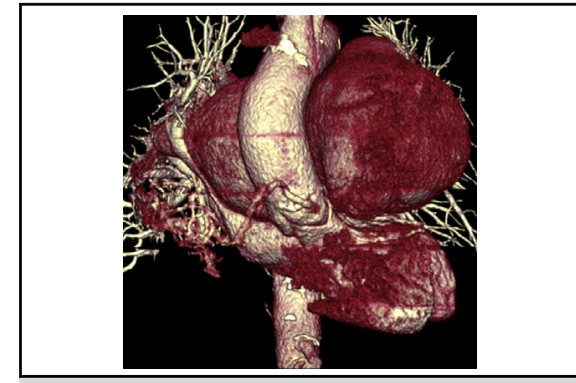

Giant aneurysm of the pulmonary arterial vasculature (CT angiography, 3D reconstruction).

\section{Central Message}

Management of PAH with giant pulmonary artery and left main compression is challenging. Causal high-risk surgery must be weighed against symptomatic therapy including left main coronary stenting

See Commentary on page e203.
A 75-year-old woman presented with progressive angina (Canadian Cardiovascular Society class III) and dyspnea (New York Heart Association functional class IV). Pulmonary arterial hypertension had externally been diagnosed years previously and treated with a phosphodiesterase type 5 inhibitor and an endothelin-receptor antagonist. Family history was positive for Marfan syndrome in her granddaughter.

Echocardiography demonstrated preserved left ventricular function but a dilated right ventricle with slightly reduced systolic function. Heart catheterization confirmed pulmonary arterial hypertension with a mean pulmonary arterial pressure of $51 \mathrm{~mm} \mathrm{Hg}$ (mean wedge pressure, $9 \mathrm{~mm} \mathrm{Hg}$; pulmonary vascular resistance, 988 dyne $\cdot \mathrm{s} \cdot \mathrm{cm}^{-5}$ ) and revealed an isolated severe left main coronary artery stenosis (Figure 1, A; arrow). Subsequent computed tomographic angiography showed a massive aneurysm of the pulmonary arterial vasculature involving the pulmonary trunk (93 mm; Figure 1, $B$ and $C$; asterisks; Figure 2; and Video 1), thus leading to external compression of the left main coronary artery (Figure 1, B; arrow). Moreover, two intimal flaps as a sign of chronic pulmonary trunk dissection were identified on magnetic resonance imaging (Figure 1, D; arrows; and Video 2). Finally, whole exome sequencing did not identify any underlying genetic disorder, especially any connective tissue disease.

After careful consideration, accounting for vessel dimensions and dissection with substantial rupture risk and for potential reversibility of the left main stenosis, the patient was scheduled for aneurysm resection and replacement with Hemashield (MAQUET Holding B.V. \& Co. $\mathrm{KG}$, Rastatt, Germany) protheses (Figure 1, $E$ and $F$; asterisk). Pathological processing showed evidence of atherosclerosis with intimal fibrosis, but no other tissue alterations.

Postoperative management was complicated by deterioration of right ventricular function, with prolonged venoarterial extracorporeal membrane oxygenation weaning and necessity of high-dose catecholamines, leading to mesenteric ischemia with transmigration peritonitis and finally multiple organ failure. The patient died 2 weeks after surgery.

The coincidence of pulmonary arterial hypertension with a giant chronically dissected pulmonary artery leading to external compression of the left main coronary artery is a rare clinical finding. ${ }^{1}$ Clear guidelines defining therapeutic standards are not available. ${ }^{2}$ The reported case illustrates the difficulties of therapeutic decision making in these patients, weighing a causal approach by 

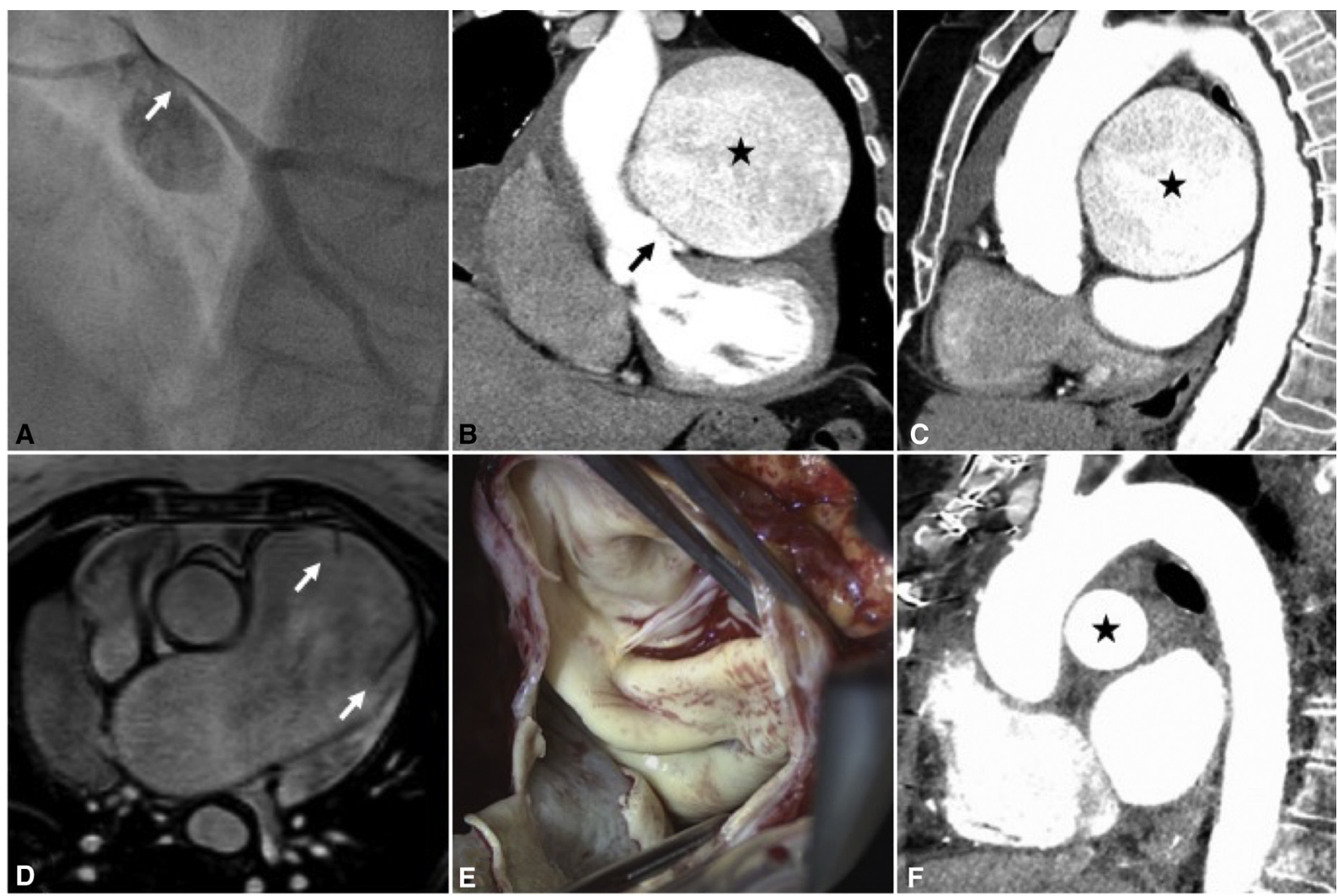

FIGURE 1. Giant dissected pulmonary artery with left main coronary artery compression and surgical treatment. A, Left main coronary artery stenosis (arrow) shown by coronary angiography; (B and C) computed tomographic angiography showing a massive aneurysm of the pulmonary artery (asterisk) with (B) external compression of the left main coronary artery (arrow); (D) magnetic resonance imaging showing 2 intimal flaps (arrows) as sign of pulmonary trunk dissection; ( $\mathrm{E}$ and $\mathrm{F}$ ) aneurysm resection and replacement with Hemashield protheses (asterisk).

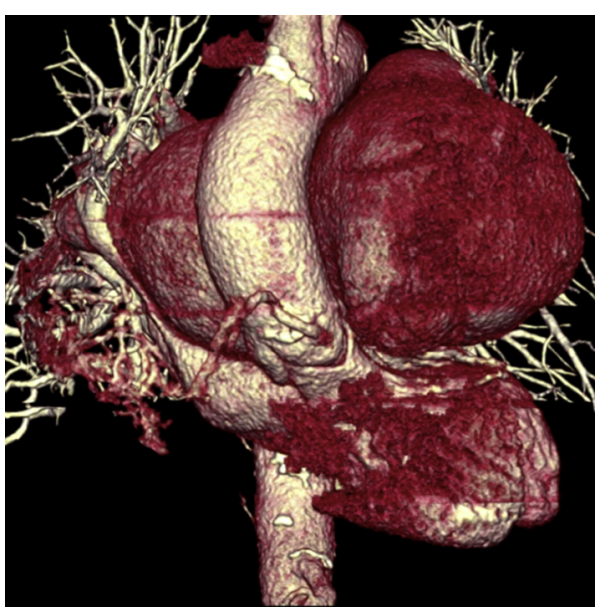

FIGURE 2. Giant aneurysm of the pulmonary arterial vasculature (computed tomographic angiography, 3-dimensional reconstruction).

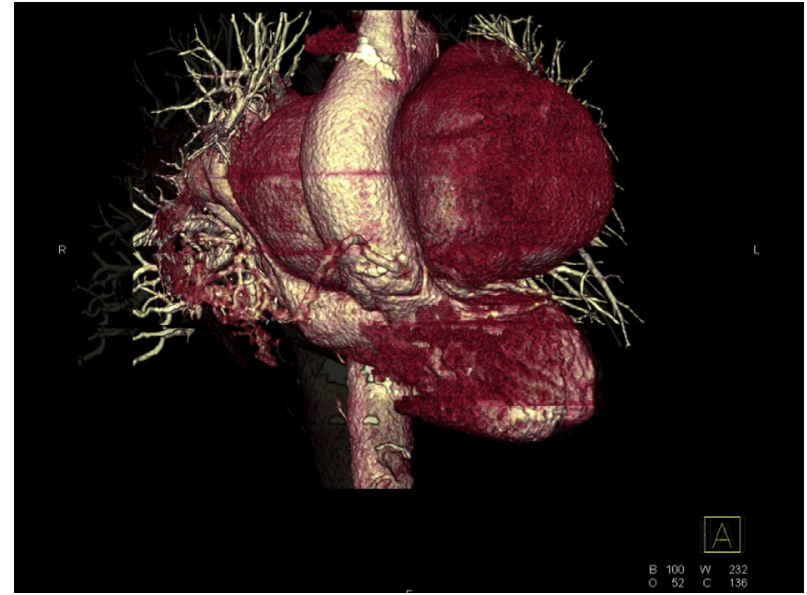

VIDEO 1. Computed tomographic angiography with 3-dimensional reconstruction of the giant pulmonary artery. Video available at: https://www. jtcvs.org/article/S0022-5223(19)30552-5/fulltext. 


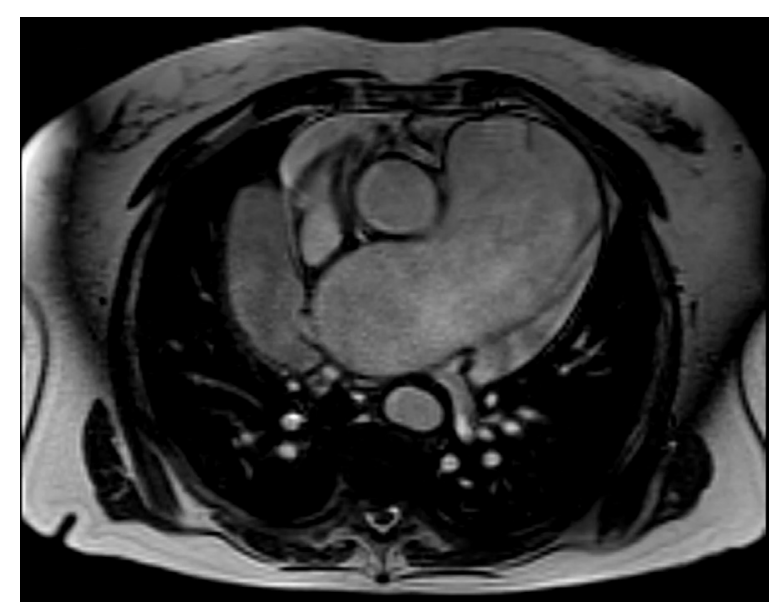

high-risk surgery ${ }^{2}$ against a symptomatic treatment option including coronary stenting. ${ }^{3}$

\section{References}

1. Duijnhouwer AL, Navarese EP, Van Dijk AP, Loeys B, RoosHesselink JW, De Boer MJ. Aneurysm of the pulmonary artery, a systematic review and critical analysis of current literature. Congenit Heart Dis. 2016;11:102-9.

2. Kreibich M, Siepe M, Kroll J, Höhn R, Grohmann J, Beyersdorf F. Aneurysms of the pulmonary artery. Circulation. 2015;131:310-6.

3. Galiè N, Saia F, Palazzini M, Manes A, Russo V, Bacchi Reggiani ML, et al. Left main coronary artery compression in patients with pulmonary arterial hypertension and angina. J Am Coll Cardiol. 2017;69:2808-17.

VIDEO 2. Magnetic resonance imaging sequence showing dissection membranes of the pulmonary artery aneurysm. Video available at: https://www.jtcvs.org/article/S0022-5223(19)30552-5/fulltext. 